\title{
POR SIEMPRE HASTA QUE SEA DIFUNTO: LA VOZ DE UN ANCIANO CHUJ
}

\author{
Recopilado por Rosalva Aída Hernández Castillo \\ CIESAS-SURESTE
}

En esta historia de vida cedemos la palabra a un grupo étnico que por mucho tiempo permaneció olvidado por investigadores sociales y funcionarios indigenistas.

Los chujes, junto con los k'anjobales y jacaltecos han sido los "olvidados" de la frontera sur de México. A excepción de algunos trabajos aislados, ${ }^{1}$ se ha profundizado poco en la realidad que viven estos grupos mayas en territorio mexicano.

Separados de sus hermanos guatemaltecos por una línea fronteriza que partió en dos una misma zona cultural, chujes, k'anjobales y jacaltecos mexicanos luchan por sobrevivir como entidades lingüísticas y culturales.

Sus actuales poblados en los municipios chiapanecos de La Trinitaria, Amatenango La Frontera y Frontera Comalapa, ${ }^{2}$ son resultado de las migraciones de indígenas guatemaltecos a territorio mexicano a fines del siglo pasado.

1 Cfr. Arzate, María Celia, "Los Riesgos del Lenguaje", en México Indigena, Instituto Nacional Indigenista núm. 17, año III, julio-agosto 1987.

Cruz Burguete, Jorge Luis, Tziscao estudio de caso del Proyecto Religión y Sociedad, CIESAS-SURESTE (en prensa), Tuxtla Gutiérrez, 1988.

De Tavira, Lourdes, "Cambios provocados por la introducción de un cultivo comercial: el café, en comunidades del área chuj de Chiapas", en Investigaciones recientes del área maya, t. III, XVII, Mesa Redonda de la Sociedad Mexicana de Antropología, San Cristóbal de las Casas, 1984.

Hernández Castillo, Rosalva Aída, Del Tzolkin a La Atalaya: los cambios en la religiosidad en una comunidad chuj-kanjobal de Chiapas. Proyecto Religión y Sociedad, CIESAS-SURESTE (en prensa), San Cristóbal de las Casas, 1988.

Tejeda Fonseca, César, Resumen Preliminar de la Comunidad de Tziscao, Chiapas (mimeografiado), Reports About Chiapas, Book I, San Cristóbal de las Casas, 1958.

2 El chuj y el k'anjobal son hablados en las colonias de Tziscao, Benito Juárez, Cuauhtémoc, El Cocal, San Vicente, Francisco I. Madero en el mu- 
La Reforma Liberal, impulsada por los gobiernos de Miguel García Granados (1871-1873) y Justo Rufino Barrios (18731885), incluyó la expropiación de terrenos comunales, por lo que grupos de indígenas guatemaltecos emigraron hacia México en busca de mejores perspectivas de vida.

La firma de los Tratados de Límites entre México y Guatemala en 1882 y la promulgación de la Ley del 15 de diciembre de 1883 referida a la colonización de terrenos nacionales, les brindó a los indígenas desposeídos la posibilidad de asentarse en la franja fronteriza, para posteriormente adquirir la nacionalidad mexicana.

Con población chuj procedente de la aldea Chaculá (municipio de Nentón) y k'anjobales de San Miguel Acatán, se formó Tżiscao en el actual municipio de La Trinitaria y con jacaltecos El Huisquilar, en Amatenango La Frontera.

Estos dos poblados dieron origen a una diáspora de colonias en la franja fronteriza donde aún se hablan esos tres idiomas mayas.

El ejido Cuauhtémoc, La Trinitaria, surgió con población que emigró de Tziscao a finales de los años treintas. ${ }^{3}$ Una parte de sus pobladores hablan el chuj y otra el k'anjobal, aunque existen ancianos que manejan con fluidez ambos idiomas.

Don Nicolás Paiz es el único sobreviviente de los fundadores de Cuauhtémoc. Su padre, Diego Paiz, fue uno de los diez jefes de familia que fundaron Tziscao a finales del siglo pasado.

A los 96 años de edad don Nicolás recuerda muchas de las costumbres de los "antiguos"; él mismo es considerado por algunos como un "antiguo".

Don Nicolás nos habla de la fundación de las colonias, de las prohibiciones del gobierno para hablar la "lengua", de la mentira que han traído las nuevas "sextas" (sectas protestantes), y su palabra toda es un testimonio de la lucha de su gente por la sobrevivencia.

nicipio chiapaneco de La Trinitaria, mientras que el jacalteco se habla en la colonia El Huisquilar, en Amatenango La Frontera y en las colonias Guadalupe Victoria, Paso Hondo, Potrerillo y El Descagal en el municipio de Frontera Comalapa.

3 La dotación oficial se entregó hasta el 11 de enero de 1946 según el expediente de la Secretaría de la Reforma Agraria (SRA). 


\section{Recopilación}

"Nuestros viejitos se quedaron sin tierra en Guatemala, quedaron de baldíos con los ricos, pues les quitaron su tierra el gobierno, por eso vinieron aquí nomás a Tziscao.

"Mi padre venía de un lugar que se llama Chaculá en Guatemala, cerca de Las Palmas, aquí nomás a la orilla de la montaña. Como no les gustaron pues estar de baldíos y en ese tiempo estaba pasando el ingeniero de la línea divisoria, entonces lo pensaron ellos y vinieron a hablar con el jefe de ingenieros aquí a Santiago, ${ }^{4}$ ahí llegaron a hablar para ver si hay permiso, para ver si hay modo. El ingeniero les dijo que vinieran dentro de cuatro días para ver la respuesta de México.

"Allá en México contestaron que sí y por eso pasaron los viejitos. Ya tiene tiempo ya de eso, con el gobierno de don Porfirio $^{5}$ todavía.

"Así llegaron a Tziscao y ahí vinieron a quedar, unos venían de Chaculá y San Mateo Ixtatán y hablaban el idioma de San Mateo y otros vienen de San Miguel y Santa Eulalia, esos hablan otro diferente. ${ }^{6}$

"Ya después llegaron unos ladinos y abundó sus animales, tenían sus 200 o 300 cabezas de animal, se regó pues 'onde quiera. Pero con tanto animal ya no da milpa, ya no se puede trabajar ya, entonces hubo pleito de animal, por eso dejamos Tziscao y vinimos a quedar aquí, hace ya como sesenta años. ${ }^{7}$

"Entonces éramos cinco los que buscamos estos terrenos: Pancho Marcos, Vicente Marcos, Pancho Jiménez, un mi hermano Diego Paiz y yo que me llamo Nicolás Paiz, pero 'hora sólo quedo yo, ya todos son difuntos ya.

* Se refiere a Santiago El Vértice, ejido fronterizo del municipio de La Trinitaria.

5 Se refiere al gobierno del general Porfirio Díaz. Según documentos del archivo ejidal de Tziscao la solicitud de tierras se hizo con fecha 5 de julio de 1887 y la resolución presidencial se emitió el 30 de septiembre de 1896.

6. Se refiere al k'anjobal.

7 Sobre la migración de parte de la población de Tziscao a El Sumidero (hoy Cuauhtémoc) existen diferentes versiones, unos hablan de la búsqueda de nuevas tierras, otros de conflictos entre la población indígena y la ladina y otros más de un rechazo a las escuelas recién fundadas en Tziscao. Parece ser que el común denominador de estos argumentos es la oposición a todos aquellos factores que atentaban contra la integridad cultural y social de la comunidad. 
"Entre los cinco trabajamos para denunciar a ver si queda colonia. Donde quiera fuimos caminando, pues ese tiempo no 'bía caminos, puro cerro va uno, no es como ahora, ese tiempo estaba muy jodido; caminamos a San Cristóbal, Tuxtla, hasta Salina Cruz fuimos.

"Nos costó mucho pero lo ganamos, formamos Cuauhtémoc, pero entonces era El Sumidero Segundo o Sumidero de Tziscao, aparte estaba El Sumidero Primero o Sumidero del Porvenir.

"Cuando hicimos la colonia el gobierno era ese que pasó después de la guerra de Carranza, ese Obregón, ese estaba, ése nos dio el permiso de pasar aquí. De su parte de él salió la orden que el que no tenga tierra que denuncie terreno nacional, porque en México todos van a tener tierra; y de por sí fue cierto porque nos dieron El Sumidero.

"Llegamos aquí y los rezadores arreglaron, lo hicieron, prendieron su candela para pedir permiso con el Dueño del lugar, el Dueño del cerro, el que vive en la montaña encantada. Entonces dijeron ellos, eso es lo que vamos a hacer, Diosito nos va a ayudar.

"Pidieron al Dueño del cerro para que esté contento, le explicaron: venimos aquí por necesidad, por pobreza, no estamos poniendo finca, es colonia lo que vamos a hacer, pues el Dueño cuando cortan árbol para poner finca se enoja.

"En esos tiempos cada ocho días encienden su candela y hacen su juntita toda la colonia, ponen candelita, ponen marimba, alegre está la fiesta, hay mucho baile y mucho bolo. ${ }^{\mathrm{s}}$

"En los cuatro esquineros del lugar hay Cruz y una frente de la iglesia, donde llegan a poner su candela, así lo hicieron

"Primero entraron dos rezadores, eran muy queridos, muy respetados, era la costumbre de la pobretada [la gente pobre].

"Por eso es que cuando llegamos a vivir aquí, estaban llenas las casas de maíz, se ve aquí en el corredor que estaban botados los coches [cerdos] de gordos, gracias a los rezadores. Ahora olvidaron la costumbre y la tierra ya no da, la tierra ya no nos ayuda ya; es que debemos respetar, de cuando en cuando hacer fiesta, como antes se hace fiesta y se quema candela en los esquineros.

8 Bolo: borracho. 
"Ya no hay rezadores ya, pero entonces la gente los buscaba, los nombraba, cuando un hombre es bueno, es honrado ése lo echan de rezador para que pida nuestra gracia con Diosito.

"Los alcaldes rezadores se saben los nombres de las Horas," lo saben, toda la gente lo sabe, todas las familias lo saben. Pero nosotros ya no sabemos porque fuimos algo lerditos y no 'veriguamos con nuestros viejitos, sino que todo los que saben se murieron y se lo llevaron.

"En ese tiempo todos los días tienen nombre, todos los mes tienen nombre. Mi papá lo sabía, lo mentaba: Rey del Mundo, Alcalde del Mundo, así lo llama para que venga a recibir su candela; algunos lo saben todavía, pero otros ya no.

"También entonces resultó la bobera gente que le dicen brujos, el mero rezador que mandaba se volvió mañoso y puro engañar gente, engañar muchachitos, entregando gente al panteón, pero todos 'veriguaron quién es y la gente se comunicó y lo mataron para que no haga maldad.

"En ese tiempo también 'bía Santo y les hacen fiesta, compran cohetes y pura alegría lo hacen el día de los patronos.

"Los de aquí son La Candelaria y el Jesús de Nazareno. La Candelaria vino de Tziscao con nosotros, la compraron nuestros viejitos hace años ya, los que quedaron les dejamos San Isidro, para que no haya pleito.

"Cuando 'bía rezadores pura lengua se habla, y las mujeres puro hüipil y corte se ponen, con faja en medio, lo traían de Guatemala, pero antes también 'bía mucho en Comitán. Uno erá igual al que tienen las refugiadas de San Mateo y el santaeulaleño ${ }^{10}$ era pura trencilla; los hombres usaban el capixay, algunos lo tienen todavía.

"Pero luego vino orden del gobierno que se hablara la castilla y se dejara el hüipil, ${ }^{11}$ por eso perdió ya, 'hora las mujeres puro vestido ponen, ya hecho en Comitán.

"Luego ya todo cambió, llegó el padre Juan de La Trinitaria y los rezadores acabaron ya.

9 Se refiere al calendario ritual o Tzolkin.

10 Gentilicio para el pueblo de Santa Eulalia, Huehuetenango, Guatemala.

11 Durante la gubernatura callista de Vistorico Grajales (1932-1936), se declararon medidas punitivas para quienes hablaran las lenguas consideradas de origen "guatemalteco" y utilizaran los trajes tradicionales. 
"Pero antes estaba muy bueno el lugar, cuando se hace costumbre todo el lugar recibe su bocadito, pura alegría era.

"Ahora olvidaron, se están regando, se están dando con otros, se alborotó la gente y ahora dicen que la candela es del Diablo, ya no es de Dios, dicen ellos los de otras sextas que los alborotaron.

"Solamente los que nos recordamos, yo tengo tres paquete de candela en mi altarcito, 'caso olvidé yo, sigo en mi costumbre, porque sé que no va a quedar contento Diosito sị lo vamos a dejar así, si lo regalamos no va a quedar contento, por eso debemos seguir nuestra costumbre.

"Hace como quince años que empezaron a llegar las sextas, los Testigos de Jehová fueron los primeros y con los refugiados llegaron más, por eso se 'bandonó la fiesta, sólo se quema candela en la casa el que recuerda, pero los jóvenes ya no hacen caso, los jóvenes burla hacen.

"Cuando llegaron esas religiones 'caso sabíamos qué eran, nadie quien lo sabe, cuando se mostraron inquietaron a las mujeres y muchachitos para que los 'compaña.

"Ahora aquí en Cuauhtémoc ya muchos son Testigos, ya no quieren la costumbre, porque los estân engañando, les trajeron su mentira y les dicen que es mejor esa religión y ahí tiene que no.

"En la Biblia de católico aparece que es mentira porque su jefe de ellos el Papa lo 'bandonó por mañoso, túvo tres mujeres y estaba en la iglesia, entonces con eso no le gustaron y lo rechazaron, ese hombre se llamaba Martín Lutero.

"Conmigo vienen los predicadores; cuando me dio un fiebre vinieron ellos a rezar, dijeron que si los 'compañaba me iba a aliviar, pero yo sabía que puro engaño son y les dije: si Dios quiere que muera voy a morir si no, no, por eso ya vieron ellos que de por' sí cada que vienen yo digo que no.

"Por eso yo sigo con mi costumbre, aunque ya no hay rezador, yo sigo sin que nadie me dé orden, pues la costumbre es según uno, si uno quiere rezar va a buscar su candelita y reza al Dueño, a la Santa Tierra, al Diosito y les pide por su cosecha, por sus animalitos, por su salud, así hago yo, siempre, hasta que sea difunto."

Cuauhtémoc, La Trinitaria, 8 de abril de 1988. 